\title{
Filmes de amido: produção, propriedades e potencial de utilização
}

\section{Starch films: production, properties and potential of utilization}

\author{
Suzana Mali ${ }^{*}$; Maria Victória Eiras Grossmann²; Fábio Yamashita ${ }^{3}$
}

\section{Resumo}

O interesse no emprego de matérias-primas provenientes de recursos renováveis para a produção de embalagens de alimentos vem crescendo. Dentre os biopolímeros mais promissores para este fim estão os amidos de diversas fontes botânicas, que são biodegradáveis, têm custo baixo e estão disponíveis em todo o mundo. Diante disto, este trabalho apresenta uma revisão bibliográfica sobre a caracterização e o potencial de utilização de filmes biodegradáveis a base de amido. Discute as propriedades mecânicas, de barreira e a cristalinidade dos filmes de amido e o efeito do uso de plastificantes sobre estas propriedades. As informações disponibilizadas mostram que existem grandes possibilidades de utilização destes materiais como embalagens de alimentos que, no entanto, dependem da produção de materiais mais estáveis às condições de armazenamento e do desenvolvimento de tecnologia de produção em escala industrial.

Palavras-chave: Embalagens biodegradáveis, biopolímeros, amido, propriedades mecânicas, propriedades de barreira.

\begin{abstract}
There is an increasing interest in the utilization of renewable resources for the production of food packaging. Among the biopolymers, starches from several sources have been considered as one of the most promising material for this purpose, and the reasons for this are that starches are biodegradable, are inexpensive and available in the worldwide. This work presents a bibliography review about biodegradable starch films characterization and potential of utilization. Discusses the starch films mechanical and barrier properties, the cristallinity and the effects of the use of plasticizers over these properties. The discussed informations indicate that exist great possibilities for these materials in food packaging, which depend on the production of more stable materials and the development of production technology in industrial scale.
\end{abstract}

Key words: Biodegradable packaging, biopolymers, starch, mechanical properties and barrier properties

\footnotetext{
1 Docente do Departamento de Bioquímica e Biotecnologia, Centro de Ciências Exatas, da Universidade Estadual de Londrina. Coordenadora e colaboradora em Projetos de Pesquisa na área de embalagens biodegradáveis de amido, orientadora do Mestrado em Biotecnologia Departamento de Bioquímica e Biotecnologia da UEL. Revisora de periódicos nacionais e internacionais. E-mail: smali@uel.br

2 Docente do Departamento de Ciência e Tecnologia de Alimentos, Centro de Ciências Agrárias, Universidade Estadual de Londrina. E-mail: victoria@uel.br

3 Docente do Departamento de Ciência e Tecnologia de Alimentos, Centro de Ciências Agrárias, Universidade Estadual de Londrina. E-mail: fabioy@uel.br

* Autor para correspondência
} 


\section{Introdução}

Estima-se que existam atualmente cerca de 121 produtores de polietileno no mundo, com uma capacidade média de 70 milhões de toneladas/ano; em 2010 esta capacidade deverá chegar a 88 milhões de toneladas. O crescimento médio anual desta produção, entre 1990 e 2005, foi de 3,5\% nos países desenvolvidos e $9 \%$ nos países em desenvolvimento (ABRE, 2008). No Brasil, do total de plásticos rígidos e filmes flexíveis produzidos, $16,5 \%$ são reciclados, o que equivale a 200 mil toneladas por ano. A maior limitação para a reciclagem é a diversidade das resinas empregadas, o que cria dificuldades para a separação e reaproveitamento das mesmas (ABIEF, 2008). A dificuldade de reciclagem da maioria das embalagens sintéticas disponíveis têm incentivado pesquisas nacionais e internacionais no sentido de incrementar e/ou desenvolver materiais biodegradáveis com características que permitam a sua utilização em embalagens.

A biodegradação é um processo natural e complexo onde compostos orgânicos, pelo intermédio de mecanismos bioquímicos, são convertidos em compostos mineralizados simples e, então, redistribuídos no meio ambiente, através do ciclo elementar, tal como o do carbono, nitrogênio e enxofre (SALAME, 1986). Em síntese, a biodegradação de um polímero é o processo intrínseco pelo qual microorganismos e suas enzimas consomem este polímero como fonte de nutrientes, em condições normais de umidade, temperatura e pressão; os polímeros melhor adaptados à biodegradação completa são os naturais, aqueles hidrolisáveis a $\mathrm{CO}_{2}$ e $\mathrm{H}_{2} \mathrm{O}$, ou a $\mathrm{CH}_{4}$ e os polímeros sintéticos que possuam estruturas próximas aos naturais (LIMA, 2004; BARDI; ROSA, 2007).

Um dos primeiros filmes plásticos biodegradáveis utilizados foi o celofane (obtido a partir do xantato de celulose), material flexível, transparente e com boas propriedades mecânicas, porém, sensível à umidade. Desde a introdução dos polímeros sintéticos na produção de embalagens, em 1950, as vendas de celofane chegaram a cair 90\% (JENKINS; HARRINGTON, 1991).

$\mathrm{Na}$ década de 1970, as pesquisas se voltaram para a introdução de amido em matrizes poliméricas sintéticas, naproporçãode $5 \mathrm{a} 20 \%$, levandoà obtenção de plásticos considerados biofragmentáveis, mas não totalmente biodegradáveis (GRIFFIN, 1977; GUILBERT; GONTARD, 1995). A partir da década de 1990, aumentou o interesseno desenvolvimento de materiais termoplásticos compostos essencialmente por amido (SOUZA; ANDRADE, 2000; MALI; GROSMANN, 2003; MALI et al., 2002, 2004a, 2005, 2006; GODBILLOT et al., 2006; ALVES et al., 2007; SHIMAZU; MALI; GROSSMANN, 2007) envolvendo a adição de plastificantes para melhorar as propriedades mecânicas. Os plastificantes devem ser compatíveis com o biopolímero e, geralmente, são adicionados na proporção de 10 a $60 \mathrm{~g} / \mathrm{g}$ matéria seca, dependo do grau de rigidez do material (GONTARD; GUILBERT; CUQ, 1993).

Os plastificantes mais indicados para serem empregados em filmes de amido são os polióis, como o glicerol e o sorbitol, que vão proporcionar a estes materiais uma melhoria nas suas propriedades mecânicas. Outros tipos de aditivos geralmente utilizados são os agentes antimicrobianos, vitaminas, antioxidantes, aromatizantes e pigmentos.

A escolha do material a ser utilizado na formulação dos filmes e revestimentos é muito importante, pois deste dependerão as interações entre os componentes do material, que poderão interferir nas propriedades de barreira, mecânicas e sensoriais dos filmes (BALDWIN; CARRIEDO, 1994).

Inúmeros estudos têm sido publicados sobre caracterização das propriedades funcionais de filmes de amido (BADER; GÖRITZ, 1994a, 1994b, 1994c; LOURDIN; DELLA VALLE; COLONNA, 1995; CHANG; CHEAH; SEOW, 2000; GARCIA; MARTINO; ZARITKY, 1998, 2000; MALI et al., 2002, 2004a, 2005; TAJLA et al., 2007; MÜLLER; YAMASHITA; LAURINDO, 2008), principalmente 
porque o amido é uma matéria-prima abundante e disponível em todo o mundo, apresenta muitas possibilidades de modificação química, física ou genética e origina filmes e revestimentos resistentes.

\section{Amido}

$\mathrm{O}$ amido pode ser obtido de diversas fontes vegetais, como cereais, raízes e tubérculos, e também de frutas e legumes, no entanto, a extração em nível comercial de amido se restringe aos cereais, raízes e tubérculos. O amido é o polissacarídeo de reserva dos vegetais e está armazenado sob a forma de grânulos, que apresentam um certo grau de organização molecular, o que confere aos mesmos um caráter parcialmente cristalino, ou semicristalino, com graus de cristalinidade que variam de 20 a $45 \%$ (YOUNG, 1984).

O amido é formado por dois tipos de polímeros de glicose, a amilose e a amilopectina, com estruturas e funcionalidade diferentes. A amilose é um polímero linear composto por unidades de D-glicose ligadas por ligações $\alpha-(1 \rightarrow 4)$, com grau de polimerização de 200 a 3000, dependendo da fonte do amido. A amilopectina é um polímero altamente ramificado, com unidades de D-glicose ligadas através de ligações $\alpha-(1 \rightarrow 4)$ e ramificações em $\alpha-(1 \rightarrow 6)$ (ELLIS et al., 1998). Variações nas proporções entre estes componentes e em suas estruturas e propriedades podem resultar em grânulos de amido com propriedades físico-químicas e funcionais muito diferentes, que podem afetar as suas aplicações industriais.

Pelo caráter semicristalino, os grânulos de amido apresentam birrefringência quando observados em microscópio óptico sob luz polarizada. A parte linear das moléculas de amilopectina forma estruturas helicoidais duplas, estabilizadas por ligações de hidrogênio entre grupamentos hidroxila, dando origem às regiões cristalinas dos grânulos. A região amorfa é composta pelas cadeias de amilose e pelas ramificações da amilopectina (SOUZA; ANDRADE, 2000). De acordo com Zobel (1964), as regiões cristalinas dos grânulos proporcionam padrões específicos de difração de raios $\mathrm{X}$, definidos com base nos espaços interplanares e na intensidade relativa das linhas de difração, que variam de acordo com a fonte botânica do grânulo. O padrão A é característico de amidos de cereais, o padrão $B$ de amidos de tubérculos e, o padrão $\mathrm{C}$, intermediário entre o $\mathrm{A}$ e o $\mathrm{B}$, característico de amido de leguminosas.

A aplicação do amido na produção de filmes se baseia nas propriedades químicas, físicas e funcionais da amilose para formar géis e na sua capacidade para formar filmes. As moléculas de amilose em solução, devido à sua linearidade, tendem a se orientar paralelamente, aproximandose o suficiente para que se formem ligações de hidrogênio entre hidroxilas de polímeros adjacentes. Como resultado, a afinidade do polímero por água é reduzida, favorecendo a formação de pastas opacas e filmes resistentes (WURZBURG, 1986).

As principais fontes comerciais de amido são o milho, a batata, o arroz, o trigo e a mandioca (ELLIS et al., 1998), porém, dentre outras fontes promissoras para a obtenção de amido estão os tubérculos de inhame (Dioscorea alata) e os grãos de aveia (Avena sativa). O amido de inhame, quando comparado com os amidos anteriormente citados, apresenta um teor médio de amilose mais elevado (Tabela 1). Os maiores teores de amilose do amido de inhame são interessantes para a confecção dos filmes (MALI et al., 2002; 2004b; 2005) e, no caso do amido de aveia, embora este apresente larga variação nos conteúdos de amilose e amilopectina, em função das diferentes cultivares que apresenta, o seu teor de lipídios parece ser promissor no desenvolvimento de filmes. De acordo com Galdeano (2007), filmes de amido de aveia são mais estáveis às condições ambientais devido ao maior teor de lipídios em relação a amidos de outras fontes. 
Tabela 1. Conteúdo de amilose e amilopectina de amidos naturais.

\begin{tabular}{lc}
\hline Fonte vegetal & Amilose (\%) \\
\hline Milho $^{\mathrm{a}}$ & 25 \\
Batata $^{\mathrm{a}}$ & 23 \\
Arroz $^{\mathrm{a}}$ & $15-25$ \\
Trigo $^{\mathrm{a}}$ & 20 \\
Mandioca $^{\mathrm{a}}$ & $16-20$ \\
Inhame $^{\mathrm{b}}$ & 30 \\
Aveia $^{\mathrm{c}}$ & $16-33$ \\
\hline
\end{tabular}

${ }^{a}$ GARCIA, 1999; ${ }^{\text {b- }}$ ALVES; GROSSMANN; SILVA, 1999 e c-WANG; WHITE, 1994

Oamidodemandiocavemsendobastanteestudado por pesquisadores brasileiros para a produção de embalagens biodegradáveis (VICENTINI; CEREDA, 1997; VICENTINI;CASTRO;CEREDA, 1999; HENRIQUE; CEREDA, 1999; OLIVEIRA; CEREDA, 2003; MALI et al., 2004a; 2005; 2006; ALVES,2007 SHIMAZU; MALI; GROSSMANN, 2007; SAKANAKA, 2007; ALVES, 2007), mesmo porque a produção de mandioca no Brasil cresceu 8,7\% entre os anos de 1997 e 2005 (ABAM, 2008). Destaca-se o Estado do Paraná, terceiro maior produtor de mandioca do País, que é responsável por $75 \%$ da produção nacional deste amido; nos últimos 15 anos a produção de amido de mandioca no Paraná sofreu forte incremento, passando de 180 mil para 430 mil toneladas/ano (ABAM, 2008).

Para a obtenção de um material termoplástico a base de amido, sua estrutura granular semicristalina precisa ser destruída para dar origem a uma matriz polimérica homogênea e essencialmente amorfa (VAN SOEST; VLIEGENTHART, 1997; SOUZA; ANDRADE, 2000; LIU, 2005). Os fenômenos que possibilitam a destruição da organização dos grânulos de amido são a gelatinização e a fusão. A gelatinização éa transformação irreversível do amido granular em uma pasta viscoelástica, fenômeno que acontece na presença de excesso de água e leva à destruição da cristalinidade e da ordem molecular do grânulo através do rompimento das ligações de hidrogênio que, inicialmente, mantinham a integridade deste. Por outro lado, quando o amido é aquecido na presença de pequenas quantidades de água, o fenômeno que indica o rompimento dos seus grânulos é conhecido como fusão, e exige de temperaturas bem maiores para acontecer que a gelatinização.

Após a gelatinização, as moléculas de amido podem começar a se reassociar através de ligações de hidrogênio, favorecendo a formação de uma estrutura mais ordenada, que, sob condições favoráveis, pode formar uma estrutura novamente cristalina; a este conjunto de alterações dá-se o nome de retrogradação ou recristalização (ZOBEL, 1964; VAN SOEST et al.; 1996). A recristalização é o mais importante fenômeno que leva ao envelhecimento dos filmes de amido, tornando-os mais rígidos e quebradiços. As condições de armazenamento de uma forma geral afetam a velocidade de recristalização, mas pode-se ressaltar o fenômeno da transição vítrea, discutido a seguir, como um importante parâmetro na determinação da velocidade de recristalização do amido.

\section{Formulação e Tecnologia de Produção de Filmes a Base de Amido}

A microestrutura e as propriedades dos filmes de amido dependem do tipo de material utilizado para a sua produção (CUQ; GONTARD; GUILBERT, 1995). Quando produzidos em escala laboratorial, se formam depois de solubilização do amido em um solvente, com formação de uma solução filmogênica 
(DONHOWE; FENNEMA, 1994) que, em seguida, é aplicada sobre um suporte e é seca para evaporação do solvente, técnica esta chamada de casting.

Na técnica do tipo casting, após a gelatinização térmica dos grânulos em excesso de água, amilose e amilopectina se dispersam na solução aquosa e, durante a secagem, se reorganizam, formando uma matriz contínua que dá origem aos filmes. De acordo com Bader e Goritz (1994 a, 1994b, 1994c), a estrutura cristalina dos filmes de amido, e conseqüentemente, as propriedades mecânicas e de barreira, são fortemente influenciadas pelas condições de secagem destes. Em filmes secos sob temperaturas superiores a $60^{\circ} \mathrm{C}$, o processo de secagem é mais rápido que a retrogradação ou recristalização (processo que leva ao envelhecimento dos filmes), gerando materiais mais estáveis ao armazenamento que filmes secos sob menores temperaturas. A umidade relativa durante a secagem dos filmes também é um fator importante, filmes secos sob maiores umidades relativas apresentam estruturas com maior grau de cristalinidade e maior teor de umidade residual, parâmetro este que tornam os filmes mais susceptíveis a alterações durante o seu o armazenamento e utilização (RINDLAVWESTLING, 1998).

O controle da espessura dos filmes produzidos por casting é uma etapa que exige atenção e é, ainda, um parâmetro pouco estudado. De acordo com Carvalho (1997), Sobral (2000a, 2000b), Mali et al. (2004a) e Galdeano (2007), este parâmetro influencia largamente as propriedades mecânicas, principalmente a força na perfuração e a permeabilidade ao vapor de água de filmes hidrofílicos. Quanto maiores as espessuras, mais resistentes à perfuração são os filmes e maior a sua permeabilidade ao vapor de água. Teoricamente, segundo a lei de difusão de Fick e a lei de sorção de Henry, a taxa de permeabilidade ao vapor de água (TPVA) de um filme plástico sintético varia com o inverso da sua espessura, enquanto que a permeabilidade ao vapor de água (PVA) deve ser constante (CUQ et al., 1996). Porém, segundo
Schwartzberg (1986), a transmissão de água através de materiais hidrofílicos é muito mais complexa devido à não linearidade das suas isotermas de sorção. O efeito da espessura sobre a PVA de filmes hidrofílicos foi observado por muitos autores (BANKER, 1966; HAGENMAIER; SHAW, 1990; GENNADIOS; WELLER; GOODING, 1994; SOBRAL, 2000a, 2000b; MALI et al., 2004a; GALDEANO, 2007), que relataram a ocorrência de filmes com diferentes capacidades de se ligarà água e, conseqüentemente, com diferentes permeabilidades, sendo formados a diferentes espessuras.

De acordo com Sobral (2000b), quando se produzem filmes por casting, o controle da espessura depende largamente da viscosidade da solução filmogênica. No caso de soluções muito viscosas, que se comportam como fluídos de Bingham (não fluem sob a ação do seu próprio peso), a solução deve ser espalhada com um equipamento conveniente, mantendo-se uma espessura da solução no suporte que permitirá o conhecimento da espessura do filme depois de seco. Quando se trabalha com soluções diluídas, o controle da espessura ocorre através do conhecimento da gramatura do material obtido. Esta técnica exige um controle rigoroso da forma do suporte e do nível da estufa, para evitar diferenças na espessura provocadas por desníveis durante a secagem.

Outro parâmetro, este largamente discutido, é o teor de plastificante empregado nos filmes de amido. Oefeitoque estescausamnas propriedades funcionais dos filmes depende não só da sua concentração, mas também do tipo de plastificante empregado (CUQ et al., 1995; McHUGH; KROCHTA, 1994; MALI et al., 2005). Para os filmes a base de amido, os plastificantes mais empregados são os polióis, como glicerol e sorbitol, porém os efeitos provocados pelo glicerol são mais acentuados que os provocados pelo sorbitol (MALI et al., 2005; CHANG; KARIM; SEOW, 2006; SHIMAZU; MALI; GROSSMANN, 2007). Quando se deseja reduzir o caráter hidrofílico dos filmes de amido, os ácidos graxos podem ser empregados como plastificantes (PARRIS et al., 1995; PETERSSON; STADING, 2005). 
Os plastificantes reduzem as forças intermoleculares e aumentam a mobilidade das cadeias dos polímeros, com diminuição de possíveis descontinuidades e zonas quebradiças, resultando assim em materiais com menores temperaturas de transição vítrea $(\mathrm{Tg})$. Favorecem a transição do material de um estado vítreo, caracterizado por uma menor mobilidade molecular entre as cadeias do polímero e por uma maior rigidez, para um estado borrachento ou gomoso, de maior mobilidade molecular e, consequentemente, maior flexibilidade. $\mathrm{O}$ decréscimo da $\mathrm{Tg}$ se reflete nas propriedades mecânicas: pode-se perceber um decréscimo da força na perfuração e o aumento da deformação dos filmes nesta situação (BILIADERIS, 1992; GONTARD; GUILBERT; CUQ, 1993; VAN SOEST; VLIEGENTHART, 1997).

$\mathrm{Na}$ realidade, os plastificantes influenciam todas as propriedades funcionais dos filmes, não só as propriedades mecânicas.APVAtende a aumentarcom o incremento do teor de plastificantes hidrofílicos, como é o caso dos polióis, em especial o glicerol. De acordo com McHugh e Krochta (1994), o aumento do teor de glicerol leva ao aumento, também, da permeabilidade aos gases de filmes hidrofilicos, ou seja, o glicerol se liga às moléculas do biopolímero, aumentando a mobilidade e diminuindo a densidade entre as suas moléculas, facilitando a transmissão dos gases através do material.

Dependendo da concentração em que são empregados, os plastificantes podem causar um efeito chamado antiplastificante, isto é, ao invés de aumentar a flexibilidade e hidrofilicidade, podem causar um efeito contrário (GAUDIN et al., 1999, 2000). Geralmente, isto ocorre quando são empregadas pequenas concentrações de plastificante (abaixo $20 \mathrm{~g} / 100$ amido), então o plastificante interage com a matriz polimérica, mas não em quantidade suficiente para aumentar a mobilidade molecular, apenas aumenta o grau de interações e a rigidez desta matriz, fenômeno este fortemente dependente das condições de armazenamento (MALI et al., 2005; SHIMAZU; MALI; GROSSMANN, 2007; CHANG; KARIM; SEOW, 2006).
Durante os últimos anos, a técnica de casting foi a mais empregada e discutida na pesquisa de filmes biodegradáveis a base de amido, mostrando bons resultados dentro do âmbito laboratorial. Porém, para a produção em escala industrial, apresenta algumas desvantagens, como tempo de processo e custo elevados, esta última em função do grande gasto energético para a secagem dos filmes. Uma solução para o problema, de acordo com Fishman et al. (2000), é a utilização do processo de extrusão para a produção em escala industrial, com as vantagens de rapidez e menores custos de produção; outro fator importante a ser considerado é que este processo já é empregado na produção de embalagens sintéticas convencionais, como as de polietileno, polipropileno, polietileno tereftalato, dentre outras.

De acordo com Van Soest e Vliegenthart (1997), várias etapas devem ser superadas para a produção industrial de plásticos biodegradáveis de amido. Em primeiro lugar, para viabilizar custos, deve ser empregada tecnologia já utilizada pela indústria de plásticos convencionais. Depois, os plastificantes e aditivos empregados devem ser biodegradáveis e, por último, os materiais desenvolvidos devem apresentar características comparáveis às dos convencionais.

Alguns trabalhos relatam a extrusão para a incorporação do amido (5-50\%) às matrizes de polímeros sintéticos convencionais, principalmente o polietileno de baixa densidade (PEBD). Como o amido tem pouca compatibilidade com os polímeros sintéticos, geralmente, em uma primeira etapa, se faz uma pré-mistura dos dois materiais, em extrusoras mono ou dupla rosca, com temperatura média de $120^{\circ} \mathrm{C}$ ao longo do processo. Na segunda etapa, com o amido já incorporado aos grânulos de PEBD, o material é novamente extrusado, ou então prensado, para a obtenção dos filmes. Em geral, quanto maior o conteúdo de amido, mais rígidos e menos resistentes às alterações de umidade são estes filmes (KIM; POMETTO, 1994; ARVANITOYANNIS et al., 1998). A biodegradabilidade destes materiais é discutível; enquanto o amido se degrada na natureza, 
o polietileno é liberado da matriz em pequenas partículas, que permanecem no meio ambiente (PETERSEN et al., 1999).

Promovendo a extrusão do amido juntamente com um plastificante (água, sorbitol, glicerol, etc.), obtém-se um material que é denominado amido termoplástico. Este material, por suas características, pode ser depois empregado na produção de filmes, por diferentes processos (CURVELO et al., 2001). Kuutti et al. (1998) produziram filmes por extrusão a partir do amido termoplástico, enquanto que outros pesquisadores empregaram a prensagem deste material para a obtenção de estruturas semi-rígidas (CURVELO et al., 2001).

Em geral, a natureza hidrofílica e semicristalina do amido dificulta o seu processamento via extrusão, ou seja, é um material muito mais susceptível a alterações de umidade e temperatura, e com maior rigidez estrutural que um polímero sintético convencional. Apesar dos problemas acima citados, o amido continua sendo um dos polissacarídeos mais promissores e estudados no desenvolvimento de embalagens e o grande desafio é adaptar o processo de produção às suas limitações (VILPOUX; AVEROUS, 2003).

Uma alternativa, que pode agregar custos, é a modificação do amido, com o principal objetivo de se obter matérias-primas com maior estabilidade às condições de armazenamento. Segundo Petersen et al. (1999), é vantajoso o emprego de amidos modificados, mesmo que com maiores custos, porque, quando se compara o amido com outros polissacarídeos, ele se mostra mais barato, menos cristalino e mais fácil de ser processado para a obtenção de materiais termoplásticos.
Diversos tipos de modificações têm sido estudadas com o objetivo de diminuir a afinidade do amido pela água, tornando assim os filmes obtidos menos susceptíveis às variações de umidade, como é o caso da introdução de ligações cruzadas, bastante empregadas para modificar quimicamente amidos de diferentes fontes botânicas, como os de milho e batata. Os amidos hidroxipropilados também têm sido largamente estudados e, de acordo com Kim (2003), à medida que se aumenta o grau de modificação em amidos hidroxipropilados, estes são degradados mais rapidamente, isto porque grupamentos hidroxipropila são mais susceptíveis à oxidação e futura degradação. Alguns pesquisadores têm relatado a necessidade de tratamentos especiais como a adição de fibras, minerais e componentes hidrofóbicos (óleos vegetais, monoglicerídeos, dentre outros) para melhorar a resistência à tração, flexibilidade e resistência ao contato com a água (ANDERSEN et al., 2001; LAWTON; SHOGREN; TIEFENBACHER, 1999, 2004; SOYKEABKAEW; SUPAPHOL; RUJIRAVANIT, 2004).

No entanto, a grande tendência na pesquisa e desenvolvimento das embalagens de amido está voltada para a combinação de amido e poliésteres biodegradáveis, produzidas através da tecnologia de co-extrusão e sopro; esta combinação permite a obtenção de materiais com estabilidade às condições ambientais e, mesmo que os poliésteres empregados apresentem valores comerciais acima dos polímeros convencionais, podem ser considerados como uma alternativa viável, já que podem ser usados em processos que permitem a escala industrial. Dentre os polímeros sintéticos biodegradáveis mais promissores e estudados em interações com o amido estão alguns poliésteres biodegradáveis, que podem vir de fonte renovável (agropolímeros), e os poliésteres oriundos de reações químicas de monômeros de origem petrolífera (Tabela 2). 
Tabela 2. Classificação dos principais poliésteres biodegradáveis disponíveis comercialmente ${ }^{a}$

\begin{tabular}{|c|c|c|}
\hline Matéria-prima & Poliéster & Nome comercial - Fabricante \\
\hline \multirow{7}{*}{ Agrícola } & \multirow{6}{*}{ Ácido polilático (PLA) } & Natureworks - Cargil-Dow LLC (USA) \\
\hline & & Lacty - Shimadzu (Japão) \\
\hline & & Lacea - Mitsui Chemicals (Japão) \\
\hline & & Heplon - Chronopol-EUA \\
\hline & & CPLA - Dainippon Ink Chem. (Japão) \\
\hline & & PLA - Galactic (Bélgica) \\
\hline & Polihidroxibutiratos (PHB, PHBV) & Biocycle - PHB industrial (Brasil) \\
\hline \multirow{9}{*}{ Petróleo } & \multirow{3}{*}{ Policaprolactona (PCL) } & CAPA - Solvay (Bélgica) \\
\hline & & Tone - Union Carbide (EUA) \\
\hline & & Celgreen - Daicel (Japão) \\
\hline & \multirow{3}{*}{$\begin{array}{c}\text { Poliésteres alifáticos } \\
\text { (PBSA - polibutileno succinato co- } \\
\text { adipato) }\end{array}$} & Enpol - Ire Chemical Ltd (Korea) \\
\hline & & Skygreen - SK Chemicals (Korea) \\
\hline & & Lunare SE - Nippon Shokubai (Japão) \\
\hline & \multirow{3}{*}{$\begin{array}{c}\text { Poliésteres aromáticos } \\
\text { (PBAT - polibutileno teretftalato co- } \\
\text { adipato) }\end{array}$} & Ecoflex - BASF (Alemanha) \\
\hline & & Biomax - Dupont (EUA) \\
\hline & & Eastar Bio - Eastman Chemical (EUA) \\
\hline
\end{tabular}

a - Adaptada de VILPOUX; AVEROUS, 2003.

\section{Propriedades de Filmes de Amido}

As propriedades físicas dos filmes de amido, assim como de embalagens sintéticas convencionais, podem mudar significativamente com alterações de temperatura e umidade relativa durante a realização dos ensaios de caracterização. Para que se possa comparar diferentes materiais e resultados de ensaios de diferentes laboratórios, é necessário padronizar as condições de temperatura e umidade relativa aos quais as amostras são submetidas durante as análises.

O termo condicionamento refere-se à estocagem da amostra em ambiente com umidade relativa constante, durante um período de tempo, a fim de se obter um estado definido da amostra em relação à atmosfera, para que possam ser obtidos resultados reprodutíveis e ainda, para se conhecer o comportamento do material em relação a determinadas condições ambientais. De acordo com Oliveira et al. (1996), existem algumas normas nacionais e internacionais que fixam padrões de condicionamento para embalagens plásticas flexíveis, dentre as quais a norma E171-94 da ASTM (American Society for Testing and Materials), a norma 554-76 da ISO (International Organization for Standarrization) e a NBR 7452 da ABNT (Associação Brasileira de Normas Técnicas).

\section{Propriedades mecânicas}

As propriedades mecânicas dos filmes de amido podem ser consideradas as mais restritivas, pois, em geral, estes materiais devem ser resistentes à ruptura e à abrasão, para proteger e reforçar a estrutura dos alimentos e, ainda, devem ser flexíveis, para adaptar-se a possíveis deformações sem se romper (SOBRAL, 2000a).

As propriedades mecânicas dependem fortemente da formulação (macromolécula, solvente, plastificante, ajustador de $\mathrm{pH}$ ) e do processo de obtenção. Dentro da formulação, o teor de plastificante, como já citado, é um importante 
fator capaz de alterar o perfil de propriedades mecânicas de um filme de amido. Filmes de amido sem plastificantes são resistentes e elásticos e, à medida que se aumenta o teor de plastificante, estes materiais se tornam mais flexíveis e deformáveis (MALI et al., 2004a, 2005); os plastificantes atuam diminuindo as forças intermoleculares entre as cadeias de amido, provocando redução da temperatura de transição vítrea e, de modo geral, a resistência cai e a flexibilidade aumenta com o incremento da concentração do plastificante (BILIADERIS, 1992; GONTARD; GUILBERT; CUQ, 1993; VAN SOEST; VLIEGENTHART, 1997; SOBRAL, 2000b).

A transição vítrea é uma transição de fase que ocorre em materiais amorfos ao serem submetidos a uma determinada temperatura, denominada de temperatura de transição vítrea (PEREZ, 1994); quando submetidos a temperaturas abaixo da $\mathrm{Tg}$, os materiais se encontram no estado vítreo e são caracterizados por uma baixa mobilidade molecular, que lhes confere certa rigidez; acima da $\mathrm{Tg}$, os mesmos se encontram no estado borrachento, de maior mobilidade molecular e, conseqüentemente, maior flexibilidade. De acordo com Forsell et al. (1997), a temperatura de transição vítrea é o parâmetro mais importante na definição das propriedades mecânicas de polímeros amorfos, em função da sua importância nos processos de recristalização e armazenamento destes materiais.

Segundo Van Soest e Vliegenthart (1997), materiais termoplásticos de amido e glicerol recristalizam, porém, este processo de rearranjo molecular pode ser acelerado quando estes materiais são armazenados em temperaturas acima da sua Tg característica. As implicações práticas da recristalização são o decréscimo da permeabilidade aos gases (MAIA; PORTE; SOUZA, 2000), da permeabilidade ao vapor de água e o aumento da rigidez dos materiais, isto acontece porque um número maior de interações acontecem e reforçam as ligações de hidrogênio entre as cadeias do amido (GARCIA; MARTINO; ZARITZKY, 2000).
Alguns trabalhos relatam os valores de $\mathrm{Tg}$ para filmes de amido produzidos por casting. Os valores obtidos para os filmes de amido de inhame (MALI et al., 2004a, 2005, 2006) estão próximos daqueles obtidos para filmes de amido de mandioca (CHANG; CHEAH; SEOW, 2000), ou seja, valores menores que $30^{\circ} \mathrm{C}$, com teor de umidade menor que $27 \%$ (base seca).

As propriedades mecânicas de filmes de amido podem ser medidas através de testes de perfuração, tração e relaxação. Nos testes de perfuração, uma sonda cilíndrica desce perpendicularmente à superfície do filme, que está fixado sobre um suporte de medida, até que ocorra o rompimento da amostra; são medidas a força e deformação na ruptura através dos gráficos de força versus deslocamento. As propriedades de tração são as mais relatadas e expressam a resistência do material ao alongamento e ao rompimento, quando submetido à tração. De acordo com Oliveira et al. (1996), as metodologias de análise das propriedades mecânicas se baseiam principalmente nas normas da ASTM: a 882-91 (ASTM D-882-91, 1996), que se aplica à determinação das propriedades de tração de filmes com espessura inferior a $1 \mathrm{~mm}$ e a 638-93 (ASTM D-638-93, 1993), para filmes com espessura igual ou superior a $1 \mathrm{~mm}$. Dentre as propriedades de tração mais estudadas estão a resistência máxima à tração, o alongamento na ruptura e o módulo de elasticidade ou de Young.

A (Tabela 3) compara o alongamento na ruptura (\%) de alguns filmes de amido e proteínas com o de filmes plásticos sintéticos. Quando comparados aos filmes biodegradáveis, os filmes sintéticos (PEBD e PEAD) apresentam alongamento na ruptura muito superior. Dentre os filmes de amido, pode-se observar que os com alto teor de amilose apresentam menor alongamento que os demais. Os filmes a base de proteína de trigo (glúten) e glicerol e metilcelulose e glicerol mostraram valores menores que os obtidos para os filmes de amido de inhame. Podese perceber que o filme de metilcelulose apresentou um aumento de cerca de 5 vezes no alongamento (\%) quando adicionado de glicerol. 
Tabela 3. Alongamento na ruptura de alguns filmes biodegradáveis e de polímeros sintéticos.

\begin{tabular}{|c|c|c|c|}
\hline Filme $^{a}$ & $\begin{array}{l}\text { Condições de } \\
\text { teste }^{b}\end{array}$ & $\begin{array}{l}\text { Alongamento na } \\
\text { ruptura }(\%)\end{array}$ & Referências \\
\hline Amido de inhame: glicerol (3:1) & $25^{\circ} \mathrm{C}$ e $64 \%$ UR & 47,0 & MALI et al. (2004) \\
\hline Amido de inhame: glicerol (2:1) & $25^{\circ} \mathrm{C}$ e $64 \%$ UR & 41,0 & MALI et al. (2004) \\
\hline Amilose: glicerol $(2,5: 1,0)$ & $50 \%$ UR & 31 & $\begin{array}{l}\text { RINDLAV-WESTLING et al. } \\
\text { (1998) }\end{array}$ \\
\hline Amilose: glicerol $(5,0: 1,0)$ & - & 10 & $\begin{array}{l}\text { LOURDIN; DELLA VALLE; } \\
\text { COLONNA (1995) }\end{array}$ \\
\hline $\begin{array}{l}\text { Amido de milho alto teor de } \\
\text { amilose intercruzado }\end{array}$ & $20^{\circ} \mathrm{C}$ e $0 \%$ UR & 10 & $\begin{array}{l}\text { DELVILLE; JOLY; BLIARD } \\
\text { (2002) }\end{array}$ \\
\hline $\begin{array}{l}\text { Amido de milho alto teor de } \\
\text { amilose intercruzado }\end{array}$ & $20^{\circ} \mathrm{C}$ e $100 \%$ UR & 12 & $\begin{array}{l}\text { DELVILLE; JOLY; BLIARD } \\
(2002)\end{array}$ \\
\hline Glúten: glicerol (6:1) & $23^{\circ} \mathrm{C}$ e $50 \%$ UR & 4,1 & McHUGH; KROCHTA, (1994) \\
\hline Glúten: glicerol (2:1) & $23^{\circ} \mathrm{C}$ e $50 \%$ UR & 30,8 & McHUGH; KROCHTA, (1994) \\
\hline Metilcelulose & - & 7,3 & DONHOWE; FENNEMA (1994) \\
\hline Metilcelulose e glicerol & - & 36,7 & DONHOWE; FENNEMA (1994) \\
\hline PEBD & $23^{\circ} \mathrm{C}$ e $50 \%$ UR & 500 & SALAME (1986) \\
\hline PEAD & $23^{\circ} \mathrm{C}$ e $50 \%$ UR & 300 & SALAME (1986) \\
\hline
\end{tabular}

a - PEBD - Polietileno de baixa densidade e PEAD - Polietileno de alta densidade.

${ }^{\mathrm{b}}$ - Temperatura $\left({ }^{\circ} \mathrm{C}\right)$ e Umidade Relativa (UR)

\section{Propriedades de barreira}

Considera-se que o processo de permeação aos gases e vapores através dos espaços intermoleculares acontece em três etapas: a) sorção e solubilização do permeante na superfície do material, b) difusão do permeante através do material devido à ação de gradientedeconcentraçãoec) dessorção e evaporação do permeante na outra face do material (KESTER; FENNEMA, 1986; MILLER; KROCHTA, 1997; MAIA; PORTE; SOUZA, 2000).

$\mathrm{Na}$ ausência de rachaduras ou cavidades, o principal mecanismo para o fluxo de gases e vapor através do filme é a difusão molecular, que compreende a abertura de espaço vazio entre os segmentos das cadeias dos polímeros, devido às oscilações dos segmentos, seguido do deslocamento do permeante dentro do espaço vazio (KESTER; FENNEMA, 1986).

\section{Permeabilidade ao vapor de água (PVA)}

A permeabilidade ao vapor de água é a medida da facilidade com que um material pode ser penetrado pelo vapor de água. A Norma ASTM E96-95 define permeabilidade como a taxa de transmissão de vapor de água através da unidade de área do material plano, a uma determinada espessura, induzida pela diferença de pressão de vapor entre duas superfícies específicas, sob condições de temperatura definidas (ASTM E96-95, 1995).

O conhecimento da permeabilidade ao vapor de água é imprescindível para a aplicação dos filmes de amido, porém, de acordo com Sobral (2000a), não é uma propriedade restritiva: um material muito permeável, como é o caso dos filmes de amido, poderá ser indicado para embalagem de vegetais frescos, enquanto que um filme pouco permeável poderá ser indicado para produtos desidratados, por exemplo. 
Em filmes hidrofílicos, a atividade de água (Aa) e a temperatura a que são submetidos influenciam grandemente as propriedades de barreira. Ao se aumentar a Aa, produz-se um inchamento excessivo da matriz polimérica, que leva a um incremento na difusão das moléculas de água e, conseqüentemente, diminui as propriedades de barreira destes materiais (BIQUET; LABUZA, 1988; KAMPER; FENNEMA, 1984). Com o aumento da temperatura, a permeabilidade ao vapor de água também aumenta, e estas variações são dependentes do teor de umidade do material (DONHOWE; FENNEMA, 1994).

$\mathrm{Na}$ (Tabela 4) encontram-se listados valores de permeabilidade ao vapor de água de alguns filmes biodegradáveis e sintéticos. Pode-se perceber que a permeabilidade é maior em filmes formados com biopolímeros do que nos filmes sintéticos convencionais.

Tabela 4. Permeabilidade ao vapor de água de filmes biodegradáveis e sintéticos ${ }^{\text {a }}$

\begin{tabular}{lcccc}
\hline \multicolumn{1}{c}{ Tipo de filme } & $\begin{array}{c}\text { Temperatura } \\
\left({ }^{\mathbf{0}} \mathbf{C}\right)\end{array}$ & $\begin{array}{c}\text { Espessura } \\
(\mathbf{m m})\end{array}$ & $\begin{array}{c}\text { Umidade } \\
\text { relativa } \mathbf{( \% )}\end{array}$ & $\begin{array}{c}\text { Permeabilidade ao vapor } \\
\mathbf{d e ~ a ́ g u a ~ x ~ 1 0 ~}^{\mathbf{1 2}} \\
\left(\mathbf{g ~ m}^{-1} \mathbf{~ s}^{-1} \mathbf{P a}^{-1} \mathbf{)}\right.\end{array}$ \\
\hline Amido e acetato de celulose & 38 & 1,119 & $100-30$ & 142 \\
Amido de inhame:glicerol $(3: 1)^{\mathrm{b}}$ & 25 & 0,07 & $75-0$ & 115 \\
Glúten & 26 & - & $100-50$ & 69,7 \\
HPC e PEG- & 21 & 0,130 & $85-0$ & 13,7 \\
MC e PEG & 21 & 0,100 & $85-0$ & 13,6 \\
Glúten e glicerol & 30 & 0,050 & $100-0$ & 5,08 \\
Glúten e ácido oléico & 30 & 0,050 & $100-0$ & 4,15 \\
Zeína e ácido oléico & 38 & 0,040 & $95-0$ & 1,48 \\
PEBD & 38 & 0,025 & $95-0$ & 0,0482 \\
PEAD & 38 & 0,025 & $97-0$ & 0,0122 \\
Folha de alumínio & 38 & 0,025 & $95-0$ & 0,000289 \\
\hline
\end{tabular}

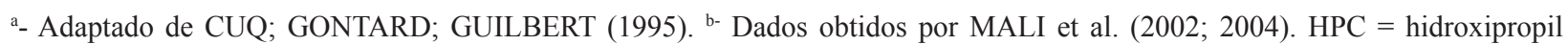
celulose; $\mathrm{MC}=$ metilcelulose PEG $=$ polietlilenoglicol; $\mathrm{PEDB}=$ polietlieno de baixa densidade, $\mathrm{PEAD}=$ polietileno de alta densidade.

\section{Permeabilidade aos gases $\left(\mathrm{CO}_{2}\right.$ e $\left.\mathrm{O}_{2}\right)$}

A utilização de filmes com permeabilidade seletiva ao oxigênio $\left(\mathrm{O}_{2}\right)$ e dióxido de carbono $\left(\mathrm{CO}_{2}\right)$ como embalagem para frutas e hortaliças in natura permite o controle das trocas gasosas por respiração e pelo desenvolvimento microbiano, podendo aumentar a vida útil dos produtos. Nos filmes hidrofílicos, o efeito da temperatura e da atividade de água sobre a permeabilidade aos gases é similar ao efeito sobre a permeabilidade ao vapor de água (DONHOWE; FENNEMA, 1994).
Os filmes formados por proteínas e polissacarídeos apresentam boas propriedades de barreira ao oxigênio, principalmente sob condições de baixa umidade relativa (Tabela 5). Em algumas condições, estes filmes podem ter permeabilidade tão baixa quanto filmes de polietileno ou PVC, como no caso dos filmes de glúten e óleo mineral, que apresentam permeabilidade ao $\mathrm{O}_{2} 800$ vezes mais baixa que os de polietileno de baixa densidade. 
Tabela 5. Permeabilidade ao $\mathrm{CO}_{2}$ e $\mathrm{O}_{2}$ de filmes biodegradáveis e filmes sintéticos a

\begin{tabular}{|c|c|c|c|c|}
\hline Tipo de filme & $\begin{array}{c}\text { Permeabilidade ao } \mathrm{O}_{2} \\
\times 10^{15} \\
\left(\mathrm{~cm}^{3} \mathrm{~m}^{-1} \mathrm{~s}^{-1} \mathrm{~Pa}^{-1}\right)\end{array}$ & $\begin{array}{l}\text { Permeabilidade ao } \\
\qquad \mathrm{CO}_{2} \times \mathbf{1 0}^{15} \\
\left(\mathrm{~cm}^{3} \mathrm{~m}^{-1} \mathrm{~s}^{-1} \mathrm{~Pa}^{-1}\right)\end{array}$ & $\begin{array}{c}\text { Temperatura } \\
\left({ }^{\circ} \mathrm{C}\right)\end{array}$ & $\begin{array}{l}\text { Atividade de } \\
\text { água (Aa) }\end{array}$ \\
\hline PEBD & 44,8 & 89,7 & 23 & 0 \\
\hline PEAD & 12,7 & 43,4 & 23 & 0 \\
\hline PVC rígido & 0,71 & - & 23 & 0 \\
\hline PET & 0,53 & 1,68 & 23 & 0 \\
\hline Celofane & 0,06 & - & 23 & 0 \\
\hline Glúten e óleo mineral & 0,08 & - & 23 & 0 \\
\hline Pectina & 59,8 & 949 & 25 & 0,96 \\
\hline Glúten & 57,6 & 1638 & 25 & 0,95 \\
\hline Amido de inhame: glicerol $(3: 1)^{b}$ & 51.300 & - & 20 & 0,75 \\
\hline Amido de milho ${ }^{c}$ & - & 29.210 .000 & 20 & 0,64 \\
\hline Amido de milho : glicerol $(1: 1)^{\mathrm{c}}$ & - & 5.690 .000 & 20 & 0,64 \\
\hline
\end{tabular}

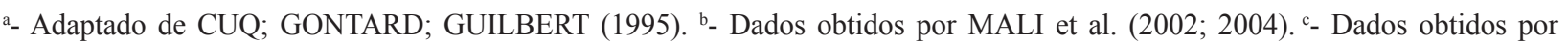
GARCÍA; MARTINO; ZARITZKY (2000).

$\mathrm{HPC}=$ hidroxipropil celulose; $\mathrm{MC}=$ metil celulose; $\mathrm{PEG}=$ polietlileno glicol; $\mathrm{PEDB}=$ polietlieno de baixa densidade, $\mathrm{PEAD}=$ polietileno de alta densidade.

\section{Cristalinidade}

Ao contrário dos materiais plásticos convencionais, os filmes de amido são sensíveis às condições de armazenamento; as cadeias de amilose e amilopectina tendem a sofrer um processo de rearranjo molecular (recristalização), como já discutido, em função do tempo e da umidade de armazenamento, processo este controlado pela transição vítrea característica do material.

A cristalinidade pode ser definida como a medida do grau de organização das moléculas de um polímero (MAIA; PORTE; SOUZA, 2000). O grau de cristalinidade nos filmes de amido pode ser resultado da organização estrutural residual das cadeias de amilose e amilopectina, dependente das condições de processamento que, possivelmente, não foram suficientes para destruir totalmente a organização molecular dos grânulos nativos, ou ainda, pode resultar do processo de recristalização ocorrido durante o seu armazenamento. O processo de recristalização acontece tanto para a amilose, quanto para a amilopectina, e tem velocidade controlada pelas condições de secagem e armazenamento dos filmes, fonte de amido e teor de amilose (VAN SOEST et al., 1996; VAN SOEST; VLIEGENTHART, 1997).

A recristalização da amilose é mais rápida que a da amilopectina, mas a associação entre ambas pode ocorrer durante este processo. A fonte de amido também influencia nos tamanhos e ramificações da amilose e da amilopectina e a cristalinidade é afetada pela presença e tamanho de cadeias laterais repetidas, característica de cada fonte botânica de amido (VAN SOEST; VLIEGENTHART, 1997; MALI et al., 2004b).

Filmes compostos exclusivamente por amilose e plastificados com glicerol apresentaram uma cristalinidade relativa de $35 \%$ quando secos sob diferentes umidades relativas (20 a 90\%), enquanto que filmes de amilopectina se mostraram amorfos quando secos sob UR de $20 \%$, mas com $32 \%$ de cristalinidade quando secos sob $90 \%$ de UR (RINDLAV-WESTLING et al., 1998).

Durante o armazenamento, o teor de plastificante afeta a velocidade de recristalização, no entanto, se a plastificação é feita exclusivamente pela água, 
pelo glicerol, ou pela combinação de ambos, os efeitos podem ser diferenciados. Em geral, um plastificante aumenta a mobilidade molecular das cadeias de um polímero e diminui a sua $\mathrm{Tg}$. Quando a plastificação é feita exclusivamente pela água, existe um aumento da cristalinidade com o aumento da umidade. Entretanto, quando o glicerol é empregado sob umidade constante e controlada, a velocidade de recristalização é reduzida, isto porque as interações amido-glicerol, provavelmente, atuem reduzindo o número de interações amido-amido. Porém, na presença de água, o glicerol, devido à sua higroscopicidade, favorece a absorção de água e, com o teor de água aumentado do sistema, a Tg cai e a recristalização é favorecida (RINDLAVWESTLING et al., 1998).

\section{Potencial de Utilização em Alimentos e Outros Usos}

A aplicação comercial de filmes de amido ou de outras macromoléculas biológicas em alimentos ainda é limitada e depende de alguns fatores como preço, processo de produção e propriedades destes materiais.

O custo deste tipo de embalagem é maior que o das embalagens tradicionais, como as de polietileno, no entanto, o consumidor em geral está mais consciente em relação à preservação do meio ambiente, aceitando muitas vezes preços mais elevados em favor desta preservação. Outros aspectos a serem considerados são as propriedades de barreira ao vapor de água inferiores que estes materiais apresentam em relação aos tradicionais e, isto pode ser resolvido, por exemplo, analisando-se a compatibilidade entre o filme e o alimento a ser embalado (RIOUX et al., 2002).

A função a ser desempenhada pela embalagem vai depender do produto alimentício e da deterioração a que este produto está submetido. Alguns filmes biodegradáveis já são comercializados na Europa para produtos alimentícios, como filmes de amido de milho usados como barreira contra gordura em produtos de confeitaria, embalagens de manteiga e margarina confeccionadas com amido de milho (90\%) e ácido polilático (10\%), ou ainda, para fins não alimentícios, como sacos de lixo a base de amido de milho e trigo disponíveis nos mercados da Itália, Finlândia e Dinamarca (HAUGAARD, 2001).

Dentre os filmes de amido produzidos em escala industrial e já comercializados está o Mater-Bi ${ }^{\circledR}$, filme de amido de milho, batata e trigo, produzido na Itália pela NOVAMONT, e que já é empregado comercialmente em sacos de lixo e outras aplicações (BASTIOLI, 2000). O Paragon ${ }^{\circledR}$, filme empregado como embalagem de alimentos que necessitam do controle de trocas gasosas, é produzido pela AVEBE na Holanda, por sopro em multicamadas com amido de batata, ácido polilático e polihidroxi-alcanoato (VILPOUX; AVEROUS, 2003).

O amido também pode ser utilizado como matériaprima para a produção de polímeros biodegradáveis obtidos por fermentação e síntese, como PLA (ácido polilático), já empregado para a produção em escala industrial de embalagens. A empresa australiana Nature Package vem produzindo embalagens biodegradáveis tipo bandejas a base de PLA para utilização em alimentos.

Dentre as possíveis aplicações dos filmes a base de amido, pode-se ressaltar o seu emprego como embalagem para frutas e hortaliças minimamente processadas; definindo-se processamento mínimo como manejo, desinfecção, embalagem e distribuição de produtos agrícolas sem alterar as suas características de produto fresco. Frutas e hortaliças sofrem deterioração progressiva imediatamente após a colheita. No mundo todo, as perdas póscolheita têm sido estimadas em cerca de $50 \%$ do material colhido e, muito disto, devido à podridão (GARCIA, 1999; NISPEROS-CARRIEDO, 1994; NISPEROS-CARRIEDO; BALDWIN, 1996; YAMASHITA et al., 2005; 2006).

O desenvolvimento de filmes comestíveis e/ou biodegradáveis, com permeabilidade seletiva aos gases, pode ser promissor no controle da respiração 
de frutas e hortaliças, funcionando como uma embalagem de atmosfera modificada. Como o ar contém, normalmente, $21 \%$ de oxigênio e apenas $0,03 \%$ de gás carbônico, qualquer processamento que modifique a concentração destes gases pode prolongar o período de armazenamento máximo dos produtos. (YAMASHITA et al.; 2005; 2006).

O emprego de embalagens que levem ao decréscimo do aporte de $\mathrm{O}_{2}$ e o aumento de $\mathrm{CO}_{2}$ em frutas e hortaliças minimamente processados, como é o caso das embalagens de amido, que apresentam baixa permeabilidade ao $\mathrm{O}_{2}$, levam à indução de uma atmosfera modificada favorável à conservação destes produtos, isto porque, nestas condições, a respiração e outros os processos metabólicos ficam retardados, assim como a produção de etileno, um metabólito acelerador da maturação. No entanto, deve-se levarem conta que uma relação $\mathrm{CO}_{2} / \mathrm{O}_{2}$ muito elevada pode levar à anaerobiose, o que também é desfavorável, resultando em injúrias metabólicas e formação de sabores e odores desagradáveis (ZHUANG et al., 1996; YAMASHITA et al.; 2005; 2006).

Mali e Grossmann (2003), comparando o comportamento de filmes a base de amido de inhame com filmes de PVC (poli - cloreto de vinila), observaram que as bandejas embaladas com PVC apresentaram a formação de gotículas de água ao longo do armazenamento, devido à sua menor PVA, o que elevou o conteúdo de umidade no interior destas bandejas, favorecendo o crescimento de microorganismos, mesmo antes da deterioração da textura dos frutos. A formação de gotículas não foi observada nas bandejas embaladas com os filmes de amido, o que representa uma vantagem, também, para a aceitabilidade pelo consumidor. A principal vantagem da utilização do filme de PVC em relação aos filmes de amido de inhame foi quanto à manutenção da firmeza dos frutos, em especial na última semana de armazenamento.
Filmes biodegradáveis inteligentes (ativos) deverão ter amplo campo de atuação no futuro. Entre as funções que deverão desempenhar, destacamse as de: controle da entrada de $\mathrm{O}_{2}$ (em alimentos facilmente oxidáveis), retenção de aditivos, seqüestro de etileno, ação antimicrobiana, etc. (BRODY, 2002). Muitas pesquisas vêm sendo realizadas neste campo, no qual a grande preocupação é garantir que o agente ativo adicionado ao filme não prejudique a inocuidade do produto embalado.

\section{Conclusões}

Os filmes e revestimentos comestíveis e/ ou biodegradáveis compõem parte importante do cenário de pesquisa nacional e internacional, com trabalhos importantes quanto à produção, caracterização e aplicação destes materiais.

Existem grandes possibilidades de aplicação para os sistemas de embalagens biodegradáveis de amido que se baseiam na abundância, baixo custo e propriedades de formação de filme deste biopolímero, dentre as quais, uma das mais estudadas, a sua utilização como embalagem de frutas e hortaliças minimamente processadas.

Em contrapartida, a utilização destes materiais depende da adequação da produção em escala industrial, do estudo da estabilidade ao armazenamento destes materiais, combinados ou não aos alimentos e, principalmente, da continuidade das pesquisas, para que os aspectos negativos e as limitações em relação à produção destes materiais sejam contornados, em especial, a baixa flexibilidade e a baixa estabilidade em condições de elevada umidade relativa.

\section{Agradecimentos}

Programa Capes/ProDoc e CNPq pelo auxílio financeiro (Projetos CNPq 577146/2008-4 e 478109/2008-3). 


\section{Referências}

ALVES, R. M. L.; GROSSMANN, M. V. E.; SILVA, R. S .S. F. Pre - gelatinized starch of Dioscorea alata functional properties. Food Chemistry, Oxon, v. 67, n. 2, p.1 23-127, 1999.

ALVES, V. D. Produção e caracterização de biomateriais a partir de fibras naturais e amidos com polibutileno adipato co-tereftalato (PBAT). 2007. Tese (Doutorado em Ciência de Alimentos) - Universidade Estadual de Londrina. Londrina.

ALVES, V .D.; MALI, S.; BELÉIA, A.; GROSSMANN, M. V. E. Effects of glycerol and amylose enrichment on cassava starch films properties. Journal of Food Engineering, Essex, v. 78, n. 2, p. 941-946, 2007.

AMERICAN SOCIETY FOR TESTING AND MATERIALS - ASTM. Standard test method for tensile properties of plastic (metric), D638M-93. Annual book of ASTM, Philadelphia, PA: American Society for Testing and Materials. 1993.

.Standard test method for water vapor transmission of material-E96-95, Annual book of ASTM, Philadelphia, PA: American Society for Testing and Materials. 1995.

Standard test method for tensile properties of thin plastic sheeting, D882-91. Annual book of ASTM, Philadelphia, PA: American Society for Testing and Materials. 1996.

ANDERSEN P .J.; ONG, S.; CHRISTENSEN, B. J.; HODSON, S. K.. Compositions and methods for manufacturing starch-based compositions. USA: Patent n. $6.168 .857,2001$.

ARVANITOYANNIS， I. ; BILIADERIA， C. G.; OGAWA, H.; KAWASAKI, N. Biodegradable films made from low-density polyethylene (LDPE), rice starch and potato starch for food packaging applications: part. 1. Carbohydrate Polymers, Barking, v. 36, n. 1, p. 89104, 1998.

ASSOCIAÇÃO BRASILEIRA DA INDÚSTRIA DE EMBALAGENS PLÁSTICAS FLEXÍVEIS - ABIEF. Disponívelem: $<$ http://www.abief.com.br/flex/flex_0018. asp.>. Acesso em: 26 fev. 2008.

ASSOCIAÇÃO BRASILEIRA DE EMBALAGEM ABRE. Disponível em <http://www.abre.org.br/meio pbr.php.>. Acesso em: 26 fev. 2008.

ASSOCIAÇÃO BRASILEIRA DE PRODUTORES DE AMIDO DE MANDIOCA - ABAM. Disponível em: $<$ http://www.mandioca.agr.br/portal/index.php.>. Acesso em: 26/ fev. 2008.
BADER, H. G.; GÖRITZ, D. Investigations on high amylose corn starch films. Part 1: Wide angle X-ray scattering (WAXS). Starch/Stärke, Weinheim, v. 46, n. 6, p. 229-232, 1994a.

. Investigations on high amylose corn starch films. Part 2: Water vapor sorption. Starch/Stärke, Weinheim, v. 46, n. 7, p. 249-252, 1994 b.

. Investigations on high amylose corn starch films.

Part 3: Stress strain behavior. Starch/Stärke, Weinheim, v. 46, n. 11, p. 435-439, 1994c.

BALDWIN, E. A.; CARRIEDO, M. O. (Ed.). Edible coatings and films to improve food quality. Lancaster (USA): Technomic Publishing Co., 1994, p.1-25.

BANKER, G. S. Film coating - theory and practice. Journal of Pharmaceutical Science, Kidlington Oxford, v. 55 , n. 1 , p. 81-89, 1966.

BARDI, M. A. G.; ROSA, D. S. Avaliação da biodegradação em solo simulado de poli ( $\varepsilon$-caprolactona), acetato de celulose e suas blendas. Revista Brasileira de Aplicações de Vácuo, São Paulo, v. 26, n. 1, p.43-47, 2007.

BASTIOLI, C. Global status of the production of biobased packaging materials. In: FOOD BIOPACK CONFERENCE. 2000, Copenhagen. Anais... Copenhagen: Denmark, 2000, p. 2-7.

BILIADERIS, C. G. Characterization of starch networks by small strain dynamic rheometry. In: ALEXANDER, R. J.; ZOBEL, H. F. Developments in carbohydrate chemistry. Saint Paul (USA): AACC, 1992, p. 87-135.

BIQUET, B.; LABUZA, T. P. Evaluation of the moisture permeability characteristics of chocolate films as an edible moisture barrier. Journal of Food Science, Chicago, v. 53, n. 4, p. 989-998, 1988.

BRODY, A. L. Active and intelligent packaging: the saga continues. Food Technology, Chicago, v. 56, n. 12, p. 6566, 2002.

CARVALHO, R. M. Desenvolvimento e caracterização de biofilmes à base de gelatina. Campinas, 1997. 128p. Dissertação (Mestrado em Engenharia de Alimentos) Universidade de Campinas. Campinas.

CHANG, Y. P.; KARIM, A. A.; SEOW, C. C. Interactive plasticizing-antiplasticizing effects of water and glycerol on the tensile properties on tapioca starch films. Food Hydrocolloids, Oxford, v. 20, n. 1, p.1-8, 2006.

CHANG, Y. P; CHEAH, P. B.; SEOW, C. C. Plasticizing - antiplasticizing effects of water on physical properties of tapioca starch films in the glassy state. Journal of Food Science, Chicago, v. 65, n. 3, p. 445-451, 2000. 
CUQ, B.; AYMARD, C.; CUQ, J. L.; GUILBERT, S. Edible packaging films based on fish myofibrillar proteins: formulation and functional properties. Journal of Food Science, Chicago, v. 60, n. 6, p. 1369-1374, 1995.

CUQ, B.; GONTARD, N.; GUILBERT, S. Edible films and coatings as active layers. In: ROONEY, M .L (Ed.). Active Food Packaging. London (UK): Chapman \& Hall, 1995, p. 111-142.

CUQ, B.; GONTARD, N.; CUQ, J. L.; GUILBERT, S. Functional properties of myofibrillar protein - based biopackaging as affected by film thickness. Journal of Food Science, Chicago, v. 61, n. 3, p. 580- 584, 1996.

CURVELO, A. A .S.; CARVALHO, A. J. F.; AGNELLI, J. A.M. Thermoplastic starch-cellulosic fiber composites: preliminary results. Carbohydrate Polymers, Barking, v. 45, n. 1, p.183-188, 2001.

DELVILLE, J.; JOLY, C.; BLIARD, C. Solid state photocrosslinked starch based films: a new family of homogenous modified starches. Carbohydrate Polymers, Barking, v. 49, n. 1, p. 71-81, 2002.

DONHOWE, I. G.; FENNEMA, O. R. Edible films and coatings: characteristics, formation, definitions and testing methods. In: KROCHTA, J. M.; BALDWIN, E. A.; NISPEROS-CARRIEDO, M.O. (Ed.). Edible coatings and films toilmprove food quality. Lancaster, PA (USA): Technomic Publishing Co., 1994, p.1-25.

ELLIS, R.P.; COCHRANE, M. P.; DALE, M. F. B.; DUFFUS, C. M.; LYNN, A.; MORRISON, I. M.; PRENTICE, R. D. M.; SWANSTON, J. S.; TILLER, S. A. Starch production and industrial use (Review). Journal of Science Food and Agriculture, London, v.77, n. 3, p.289-311, 1998.

FISHMAN, M. L.; COFFIN, D. R.; KONSTANCE, R. P.; OWNULATA, C. I.. Extrusion of pectin/starch blends plasticized with glycerol. Carbohydrate Polymers, Barking, v. 41, n. 4, p. 317-325, 2000.

GALDEANO, M. C. Filmes e laminados biodegradáveis de amido de aveia com diferentes plastificantes, produzidos por casting e extrusão. 2007. Tese (Doutorado em Ciência de Alimentos) - Universidade Estadual de Londrina. Londrina

GARCIA, M. A. Desarrollo de recubrimientos de matriz amilósica para vegetales. 1999. Tese (Doutorado) Departamiento de Química, Facultad de Ciência Exactas, Universidad Nacional de La Plata, Argentina.

GARCIA, M. A.; MARTINO, M. N.; ZARITZKY, N. E. Microstructural characterization of plasticized starchbased films. Starch/Stärke, Weinheim, v. 52, n. 4, p. 118124,2000 .
Starch - base coatings: effect on refrigerated strawberry (Fragaria ananassa) quality. Journal of Food Science and Agriculture, London, v. 76, n. 1, p. 411-420, 1998.

GAUDIN, S.; LOURDIN, D.; LE BOTLAN, D.; ILARI, J. L.; COLLONA, P. Plasticisation and mobility in starchsorbitol films. Journal of Cereal Science, London, v. 29, p. 273-284, 1999.

GAUDIN, S.; LOURDIN, D.; FORSSEL, P. M.; COLONNA, P. Antiplasticisation and oxygen permeability of starch-sorbitol films. Carbohydrate Polymers, Barking, v. 43, n. 1, p. 33-37, 2000.

GENNADIOS, A.; WELLER, C. L.; GOODING, C. $\mathrm{H}$. Measurements errors in water vapor permeability of highly permeable, hydrophilic edible films. Journal of Food Engineering, Essex, v. 21, n. 2, p. 395-409, 1994.

GODBILlOT, L.; DOLE, P.; JOLY, C.; ROGÉ, B.; MATHLOUTHI, M. Analysis of water binding in starch plasticized films. Food Chemistry, Oxon, v. 96, n. 3, p. 380-386, 2006.

GONTARD, N.; GUILBERT, S.; CUQ, J. L. Water and glycerol as plasticizers affect mechanical and water vapor barrier properties of an edible wheat gluten film. Journal of Food Science, Chicago, v. 58, n. 1, p. 206-211, 1993.

GRIFFIN, G. J. L. Synthetic resin sheet material. [S.1.:s.n], 1977. (US Patent n. 4.021.388).

GUILBERT, S.; GONTARD, N. Technology and applications of edible protective films. In: VII BIOTECHNOLOGY AND FOOD RESEARCH. New shelf-life technologies an safety assessments, Helsink, Finland, p. 49-60, 1995.

HAGENMAIER, R. D.; SHAW, P. E. Moisture permeability of edible films made with fatty acid and hydroxypropyl methylcelulose. Journal of Agricultural and Food Chemistry, Washington, v. 38, p. 1799-1803, 1990.

HAUGAARD, V. K. Potential food applications of biobased materials. An EU-concerted action project. Starch/Stärke, Weinheim, v. 5, n. 1, p. 189-200, 2001.

HENRIQUE, C. M.; CEREDA, M. P. Utilização de biofilmes na conservação pós-colheita de morango (Fragaraia ananassa Duch) CV IAC Campinas. Ciência e Tecnologia de Alimentos, Campinas, v. 19, n. 2, p. 231233, 1999.

JENKINS, W. A.; HARRINGTON, J. P. The chemistry and manufacture of polymers used in packaging. In: . (Ed.). Packaging foods with plastics. Lancaster (USA): Technomic Publishing Co., 1991. p. 35-36. 
KAMPER, S L.; FENNEMA, O. Water vapor permeability of an edible, fatty acid, bilayer film. Journal of Food Science, Chicago, v. 49, n. 6, p. 1482-1485, 1984.

KESTER, J. J.; FENNEMA, O. Edible films and coatings: a review. Food Technology, Chicago, v. 40, n. 12, p. 4759, 1986.

KIM,M.Evaluation ofdegradability of hydroxypropylated potato starch / polyethylene blend films. Carbohydrate Polymers, Barking, v. 54, p. 173-181, 2003.

KIM, M.; POMETTO, L. Food packaging potential of some degradable starch - polyethylene plastics. Journal of Food Protection, Des Moines, v. 57, n. 11, p. 10071012, 1994.

KUUTTI, L.; PELTONEN, J.; MYLLÄRINEN, P.; TELEMAN, O.; FORSSELL, P. AFM in studies of thermoplastic starches during ageing. Carbohydrate polymers, Barking, v. 37, n. 1, p. 7-12, 1998.

LAWTON, J. W.; SHOGREN, R. L.; TIEFENBACHER, K. F. Effect of batter solids and starch type on the structure of baked starch foams. Cereal Chemistry, London, v. 76, n. 5, p. 682-687, 1999.

. Aspen fiber addition improves the mechanical properties of baked cornstarch foams. Industrial Crops and Products, Amsterdan, v. 19, n .1, p. 41-48, 2004.

LIMA, S. L. T. Reciclagem e biodegradação de plásticos. Revista Cientifica do IMAPES, Sorocaba, v. 2, n. 2, p. 28-34, 2004.

LIU, Z. Edible films and coatings from starches. In: HAN, J. H. (Ed.). Innovations in food packagings, Elsevier: Amsterdam, The Netherlands, 2005. p. 318-336.

LOURDIN, D.; DELLA VALLE, G.; COLONNA, P. Influence of amylose content on starch films and foams. Carbohydrate Polymers, Barking, v. 27, n. 2, p. 261-270, 1995.

MAIA, L. H; PORTE, A.; SOUZA, V. F. Filmes comestíveis: aspectos gerais, propriedades de barreira a umidade e oxigênio. Boletim do CEPPA, Curitiba,v. 18, n. 1, p. 105-128, 2000.

MALI, S., GROSSMANN, M. V. E., GARCÍA, M. A., MARTINO, M. M.; ZARITZKY, N. E. Microstructural characterization of yam starch films. Carbohydrate Polymers, Barking, v. 50, n. 2, p. 379-386, 2002.

Barrier, mechanical and optical properties of plasticized yam starch films. Carbohydrate Polymers, Barking, v. 56, n. 2, p. 129-135, 2004a.

. Mechanical and thermal properties of yam starch films. Food Hydrocolloids, Oxford, v. 19, n. 1, p. 157164, 2005.
Effects of controlled storage on thermal, mechanical and barrier properties of plasticized fillms from different starch sources. Journal of Food Engineering, Essex, v. 75, n. 4, p. 453-460, 2006.

MALI, S., KARAM, L.B, RAMOS, L.P.; GROSSMANN, M. V. E. Relationships among the composition and physicochemical properties of starches with the characteristics of their films. Journal of Agricultural and Food Chemistry, Washington, v. 52, n. 25, p. 7720-7725, 2004b.

MALI, S.; GROSSMANN, M. V. E. Effects of yam starch films on storability and quality of fresh strawberries (Fragaria ananassa). Journal of Agricultural and Food Chemistry, Washington, 2003. p.7055-7011.

McHUGH, T. H; KROCHTA, J. M. Sorbitol- vs glycerol - plasticized whey protein edible films: integrated oxygen permeability and tensile property evaluation. Journal of Agricultural and Food Chemistry, Washington, v. 42, n. 4, p. 841-845, 1994.

MILLER, K. S.; KROCHTA, J. M. Oxygen and aroma barrier properties of edible films: a review. Food Science and Technology, Chicago, v. 8, n. 7, p. 228-237, 1997.

MÜLLER; C. M. O., YAMASHITA, F; LAURINDO, J. B. Evaluation of the effects of glycerol and sorbitol concentration and water activity on the water barrier properties of cassava starch films through a solubility approach. Carbohydrate Polymers, Barking, v. 72, n. 1, p. 82-87, 2008.

NISPEROS-CARRIEDO, M. O. Edible coatings and films based on polysaccharides. In: KROCHTA, J. M.; BALDWIN, E. A.; NISPEROS-CARRIEDO, M. O. (Ed.). Edible coatings and films to improve food quality. Lancaster, PA (USA): Technomic Publishing Co., 1994. p. 305-330.

NISPEROS-CARRIEDO, M. O.; BALDWIN, E. A. Edible coatings for whole and minimaly processed fruits and vegetables. Food Australia, North Sydney, v. 48, n. 1, p. 27-31, 1996.

OLIVEIRA, L. M.; SARANTÓUPOLOS, C. I. G. L.; CUNHA, D. G.; LEMOS, A. B. Ensaios para avaliação de embalagens plásticas flexíveis. Campinas: Centro de Tecnologia de Embalagem, 1996.

OLIVEIRA, M. A. O.; CEREDA, M. P. Pós-colheita de pêssegos (Prinus persica L. Bastsch) revestidos com filmes a base de amido como alternativa à cera comercial. Ciência e Tecnologia de Alimentos, Campinas, v. 23, n. 1, p. 28-33, 2003.

PARRIS, N.; COFFIN, D. R.; JOUBRAN, R. F.; PESSEN, H. Composition factors affecting the water vapor permeability and tensile properties of hydrophilic 
films. Journal of Agricultural and Food Chemistry, Washington, v. 43, n. 6, p. 1432-1435, 1995.

PEREZ, J. Theories of liquid-glass transition. Journal of Food Engineering, Essex, v. 22, n. 1, p. 89-114, 1994.

PETERSEN, K.; VAEGGEMOSE, N.P.; BERTELSEN, G.; LAWTHER, M.; OLSEN, M. B.; NILSSON, N. H.; MORTENSEN, G. Potential of biobased materials for food packaging. Trends in Food Science and Technology, Kidlington Oxford, v. 10, n. 2, p. 52-68, 1999.

PETERSSON, M.; STADING M. Water vapour permeability and mechanical properties of mixed starch-monoglyceride films and effect of film forming conditions. Food Hydrocolloids, Oxford, v. 19, n. 2, p. 123-132, 2005.

RINDLAV-WESTLING, A.; STADING, M.; HERMANSSON, A.; GATENHOLM, P. Structure, mechanical and barrier properties of amylose and amylopectin films. Carbohydrate Polymers, Barking, v. 36, n. 2/3, p. 217-224, 1998.

SAKANAKA, L. S. Confecção de filmes biodegradáveis por extrusão de blendas de amido termoplástico e polibutileno succinato co-adipato (PBSA). 2007. Tese (Doutorado em Ciência de Alimentos) - Universidade Estadual de Londrina. Londrina.

SALAME, M. Barrier polymers. In: BAKER, M. The Wiley encyclopedia of packaging technology. New York, USA: Wiley, 1986. p. 48-54.

SCHWARTZBERG, H. G. Modeling of gas vapor transport through hydrophilic films. In: MATHLOUTHI, M. (Ed.). Food packaging and preservation. New York, USA: Elservier Science Publishing Co., 1986. p. 115 -135 .

SHIMAZU, A. A.; MALI, S.; GROSSMANN, M. V. E. Efeitos plastificante e antiplastificante do glicerol e do sorbitol em filmes biodegradáveis de amido de mandioca. Semina Ciências Agrárias, Londrina, v. 28, n. 1, p. $79-$ 88, 2007.

SOBRAL, P. J. A. Influência da espessura de biofilmes feitos à base de proteínas miofibrilares sobre suas propriedades funcionais. Pesquisa Agropecuária Brasileira, Brasília, v. 35, n. 6, p. 1-14, 2000a.

Proteínas de origem animal na tecnologia de biofilmes. 2000b. 156p. Tese (Tese de Livre Docência)Universidade de São Paulo. Pirassununga.

SOUZA, R. C. R; ANDRADE, C. T. Investigação dos processos de gelatinização e extrusão de amido de milho. Polímeros: Ciência e Tecnologia, São Paulo, v. 10, n. 1, p. 24-30, 2000.
SOYKEABKAEW N.; SUPAPHOL P.; RUJIRAVANIT R. Preparation and characterization of jute and flax reinforced starch-based composite foams. Carbohydrate Polymers, Barking, v. 58, n. 1, p. 53-63, 2004.

TAJLA, R. A.; HELÉN, H.; ROOS, Y. H.; JOUPPILA, K. Effect of various polyols and polyol contents on physical and mechanical properties of potato starch-based films. Carbohydrate Polymers, Barking, v. 67, n. 3, p. 288-295, 2007.

VAN SOEST, J. J. G.; HULLEMAN, S. H. D.; WIT, D.; VLIEGENTHART, J. F. G. Cristallinity in starch bioplastics. Industrial Crops and Products, Amsterdan, v. 5, n. 1, p. 11-22, 1996.

VAN SOEST, J. J. G; VLIEGENTHART, J. F. G. Crystallinity in starch plastics: consequences for material properties. Trends in Biotechnology, Kidlington Oxford, v. 15 , n. 6 , p. 208- 213, 1997.

VICENTINI, N. M.; CASTRO, T. M. R,; CEREDA, M. P. Influência das películas de fécula de mandioca na qualidade pós-colheita de frutos de pimentão (Capsicum annuum L.). Ciência e Tecnologia de Alimentos, Campinas, v. 19, n. 1, p. 127-130, 1999.

VICENTINI, N. M.; CEREDA, M. P. Utilização de películas de fécula de mandioca natural e modificada na conservação pós-colheita de frutos de pepino (Cucumus sativus L.). In: WORKSHOP SOBRE BIOPOLÍMEROS. Anais... Pirassununga, 1997, p. 89-93.

VILPOUX, O.; AVEROUS, L. Culturas de tuberosas amiláceas latino americanas. In: CEREDA, M. P.; VILPOUX,O.(Coord.).Tecnologia, usosepotencialidades de tuberosas amiláceas Latino Americanas. São Paulo: Cargill, 2003. v.3. p. 500-530.

WANG, L. Z.; WHITE, P. J. Structure and properties of amylose, amylopectin and intermediary materials of oat starches. Cereal Chemistry, London, v. 71, n. 3, p. 263268, 1994.

WURZBURG, O. B. Cross - linking starches. In: WURZBURG, O. B. Modified starches: properties and uses. Boca Raton: CRC Press, 1986. p. 41-53.

YAMASHITA, F., NAKAGAWA, A., VEIGA, G. F., MALI, S., GROSSMANN, M. V. E. Filmes biodegradáveis para aplicação em frutas e hortaliças minimamente processadas. Brazilian Journal of Food Technology (ITAL), Campinas, v. 8, n. 3, p. 335-343, 2005.

Embalagem ativa para frutos de acerola. Brazilian Journal of Food Technology (ITAL), Campinas, v. 9, n. 4, p. 95-100, 2006. 
YOUNG, H. Fractionation of starch. In: WHISTLER, R. L.; BEMILLER, J. N.; PASCHALL, E. F. (Ed.). Starch chemistry and technology. 2.ed. Orlando,USA: Academic Press, 1984. p. 249-283.

ZHUANG, R.; BEUCHAT, L.R.; CHINNAN, M.S.; SHEWFELT, R.L.; HUANG, Y.W. Inactivation of
Salmonella montevideo on tomatoes by applying cellulose based edible films. Journal of Food Protection, Des Moines, v. 59, n. 8, p. 808-812, 1996.

ZOBEL, W. Potato starch. In: WHISTLER R. L. Methods in carbohydrate chemistry. New York, USA: Academic Press, 1964. v. 4. 
